\title{
O MAR E A ALMA: METÁFORAS MARINHAS EM TERRITÓRIO ALEMÃO ${ }^{1}$
}

\author{
Marco Aurélio WERLE ${ }^{2}$
}

- RESUMO: O artigo explora algumas metáforas marinhas que surgem no pensamento alemão de Leibniz a Goethe, com o intuito de indicar como se desenvolvem certos temas de estética, tais como a noção de alma, de linguagem, de criação artística e de relação dialética entre forma e conteúdo. Passando por autores como Leibniz, Winckelmann, Herder, Goethe e Kant, pretende-se mostrar como, por meio desse desenvolvimento, se constitui uma visão de homem mais ampliada, que não se define mais somente pelo entendimento, mas envolve elementos inconscientes e afetivos.

- PALAVRAS-CHAVE: estética; filosofia alemã; época de Goethe; literatura; arte; filosofia.

Para Franklin de Matos, recordando a Ilha Grande.

O que se lerá a seguir constitui um passeio por algumas imagens do pensamento alemão compreendido entre Leibniz e Goethe, durante o qual se pretende indicar certas relações reflexivas, sem o intuito de explorá-las do ponto de vista estritamente teórico, mas permitir que nos mostrem ou nos deixem entrever algo, justamente enquanto impressões figurativas.

1 Esse artigo é o resultado de uma palestra proferida no Anfiteatro do Campus da Unesp de Marília em 29 de março de 2007. Agradeço ao Prof. Dr. Ubirajara Rancan de Azevedo Marques, coordenador do grupo de pesquisa "Em torno do iluminismo" e ao Departamento de Filosofia da Unesp/ Marília pelo convite.

2 Professor Assistente Doutor do Departamento de Filosofia e do Programa de Pós-Graduação em Filosofia da Universidade de São Paulo-Usp. Artigo recebido em mar/07 e aprovado para publicação em abr/07. 


\section{O bramido do mar: Leibniz}

No dizer de Alfred Bäumler, a importância de Leibniz para a constituição de um pensamento de cunho estético, na passagem do século XVII para o XVIII, passa pela maneira com que apreende a alma, à diferença de Descartes, que em oposição à Antigüidade e as teorias dominantes de sua épo$\mathrm{ca}$, compreendeu a alma como espírito puro. Descartes permitiu que se alcançasse o infinito, mas, prossegue Bäumler, assim "a alma tornou-se uma res cogitans transparente, na qual passou a não existir mais nada de obscuro, nenhum enigma, nenhum mistério. Por essa razão, a psicologia cartesiana não conseguiu dar conta do fenômeno do gosto" (Bäumler, 1967, p.38). Para o autor do sistema da harmonia preestabelecida, no entanto, nossa alma não é uma simples res cogitans, bem como também não é uma tabula rasa que se assemelha a lousas vazias (como pretende o "ilustre inglês Locke"), e sim

existe a todo momento uma infinidade de percepções em nós, porém sem a percepção e sem reflexão: mudanças na própria alma, das quais não nos apercebemos, pelo fato de as impressões serem ou muito insignificantes e em número muito elevado, ou muito unidas, de sorte que não apresentam isoladamente nada de suficientemente distintivo: porém, associadas a outras, não deixam de produzir o seu efeito e de fazer-se sentir ao menos confusamente (nos Novos ensaios sobre o entendimento humano, escritos em 1701-1704 e publicados somente em 1765). (Leibniz, 1984, p.11-2)

A percepção da alma se organiza segundo a parte e o todo, num condicionamento recíproco, tal como cada onda em particular diante do bramido do mar como um todo.

Para melhor julgar sobre as pequenas percepções que somos incapazes de distinguir em meio à multidão delas, costumo utilizar o exemplo do bramido do mar. Para ouvir este ruído como se costuma fazer, é necessário que ouçamos as partes que compõem este todo, isto é, os ruídos de cada onda, embora cada um destes pequenos ruídos só se faça ouvir no conjunto confuso de todos os outros conjugados, isto é, no próprio bramir, que não se ouviria se esta onda que o produz estivesse sozinha. Com efeito, é necessário afirmar que somos afetados, por menos que seja, pelo movimento desta minúscula onda, e que temos alguma percepção de cada um dos seus ruídos, por menores que sejam; se assim não fosse, não teríamos a percepção de cem mil ondas, pois cem mil ondas nunca poderiam produzir alguma coisa. (idem, p.12)

Ao ressaltar desse modo a alma, em contraste com o papel do entendimento na constituição da relação do homem com o mundo exterior, Leibniz 
acaba por dar espaço, no século XVIII, a elementos inconscientes ou profundos, os quais tornam-se terreno fértil tanto para os temas do gosto quanto para o desabrochar do individualismo na literatura. Tomemos como exemplo o romance epistolar de Goethe, Os sofrimentos do jovem Werther [1772], em particular a carta que escreve Werther no dia 10 de maio de 1771, na qual inicialmente o jovem expõe sua disposição de ânimo daquele dia: "uma alegria maravilhosa [eine wunderbare Heiterkeit] se apropriou de toda a minha alma, tal como a doce manhã da primavera, que desfruto com todo o meu coração" (Goethe, s.d., p.6). Sozinho em contato com a natureza que o envolve, o coração de Werther é profundamente tocado pelo vale, pela floresta, pela campina, pela grama, pelos raios generosos do sol, pelo riacho, enfim, por todo o pequeno mundo de insetos sob as árvores, o que o impele a tentar colocar tudo isso em palavras ou numa tela (já que a pintura é o seu passatempo predileto). "Há! Se tu pudesses expressá-lo novamente, pudesses transmitir [einhauchen] tudo isso ao papel, o que vive tão plena e ardorosamente em ti, para que pudesse ser o espelho de tua alma, assim como tua alma é o espelho do deus infinito!" (ibidem). Entretanto, diante da violência e da glória desses fenômenos, as impressões são muito fortes e Werther não consegue fixá-las, isto é, "sucumbe" [gehe darüber zugrunde...].

Se o protagonista de Goethe aspira pelo todo por meio da pintura, mais ou menos cem anos depois, em 1876, o destemido herói Siegfried será pintado expressivamente por Richard Wagner num quadro musical análogo. Situado para além do princípio da razão suficiente, Siegfried, além de aprender a decifrar os pensamentos dos homens, adquiriu também o dom de compreender os sons dos pássaros, que o conduzem tanto para o Tesouro dos Nibelungos quanto para a Walquíria Brünnhilde. Comentando o segundo ato da ópera Siegfried, ${ }^{3}$ intitulado "Murmúrios da floresta", Maria Lúcia Monteiro afirma: "Sentado à sombra de uma árvore, Siegfried reflete sobre suas origens, que não conhece bem, indagando como seriam seus pais, com quem jamais conviveu. A música passa para o ouvinte todo o encantamento da natureza, a atmosfera de magia de uma floresta de contos de fadas" (Wagner, 1989, p.6-7).

Antevendo esses desdobramentos ou talvez a triste ou trágica sina de Werther e de Siegfried, o próprio Leibniz considerou essas pequenas percepções "mais eficazes do que se pensa. São elas que formam este não sei que [je ne sais quoi], esses gostos [ces gouts], essas imagens das qualidades dos sentidos, claras no conjunto, porém, confusas nas suas partes indi-

3 Terceiro drama que compõe a tetralogia $O$ anel do Nibelungo. O Ouro do Reno constitui a abertura da Tetralogia, sendo o primeiro drama intitulado A Walquíria, o segundo Siegfried, o terceiro O crepúsculo dos deuses e o último drama Parsifal. 
viduais, essas impressões que os corpos circunstantes produzem em nós, que envolvem o infinito, essa ligação que cada ser possui com todo o resto do universo" (Leibniz, 1984, p.12).

\section{Profundezas calmas e superfícies agitadas: Winckelmann}

Mas, onde buscar essa alma em sua amplitude e particularidade originária, de onde nasce ou emerge o bramido e como alcança expressão? Soltando as feras ou avançando mar adentro, o século XVIII procurará desbravar esse oceano e realizará uma expedição em direção ao estrangeiro, na busca do que é próprio, na medida em que o estrangeiro se liga ao próprio como o próprio ao estranho, segundo a intuição do poeta Friedrich Hölderlin. ${ }^{4}$ Winckelmann encontrará na Antigüidade uma resposta para os temas do gosto. Suas Reflexões sobre a imitação das obras gregas na pintura e na escultura (1755) abrem com as seguintes palavras: "O bom gosto, que mais e mais se expande no mundo, começou a se formar, em primeiro lugar, sob o céu grego" (Winckelmann, 1975, p.3). Com efeito, o sucesso da arte grega se deve em grande parte à natureza generosa e à relação atlética e saudável que esses habitantes de ilhas mantiveram com ela.

A causa e o fundamento dos méritos que a arte alcançou entre os gregos devem ser atribuídos em parte à influência do céu, em parte à constituição e ao governo e ao modo de pensar decorrente deles, bem como também em nenhum grau menor por causa da atenção que se deu ao artista e ao emprego e à aplicação da arte entre os gregos. (idem, 1993, p.128)

A arte grega alcançou essa fortuna por ter conseguido equilibrar a bela natureza com o caráter divino e ideal, que se anuncia na fórmula da nobre simplicidade e grandeza serena:

Enfim, o caráter geral, que antes de tudo distingue as obras gregas, é uma nobre simplicidade e uma grandeza serena tanto na atitude como na expressão. Assim como as profundezas do mar permanecem sempre calmas, por mais furiosa que esteja a superfície, da mesma forma a expressão nas figuras dos gregos mostra, mesmo nas maiores paixões, uma alma magnânima e ponderada. (idem, 1975, p.53; 1993, p.20)

4 Tomo essas expressões da carta de Hölderlin (que apreciava o mar, mas, sobretudo, os rios caudalosos como o Reno e o Danúbio) a Casimir Ulrich Böhlendorf, de 04/12/1801: "Nada é mais difícil de aprender do que o livre uso do nacional. Acredito que, para nós, a clareza da apresentação é, originariamente, tão natural como foi, para os gregos, o fogo do céu ... mas o próprio deve ser apreendido como o estranho. Os gregos são imprescindíveis para nós" (Hölderlin, 1994, p.132). 
Essa dialética entre profundidade e superfície permite situar o grupo escultórico do Laocoonte ${ }^{5}$ como estando perfeitamente em sintonia com o modo de pensar grego, tal como Winckelmann o compreendia. Mas, sua atenção estava voltada com mais intensidade para a profundidade do que para a superfície; nele o historiador e idealista pulsava mais do que o crítico de arte. Mesmo quando penetra no terreno da crítica, Winckelmann vê as obras de arte essencialmente emanando de um fundo, como ocorre na "descrição" da estrutura muscular do torso de Hércules, do qual afirma:

Assim como, junto ao movimento que se ergue no mar, a superfície antes calma cresce a partir de uma inquietação nebulosa nas ondas que brincam entre si e cada uma delas se entrelaça com uma outra ou é novamente impulsionada, da mesma maneira aqui um músculo, inflado de modo suave e um pouco suspendido, penetra num outro, e um terceiro, que se ergue entre os dois e parece intensificar o movimento de ambos, se perde no movimento arrastando igualmente o nosso olhar. (idem, s.d., p.5-6)

O crítico de arte se revelará com toda força em Lessing. Será no Laocoonte ou os limites da pintura e da poesia que se indagará pelo problema da superfície e se estabelecerá um questionamento sobre o modo de como o princípio se plasma na aparência. A isso se segue uma delimitação da especificidade da pintura e da poesia (ut pictura poiesis), ou melhor, da liberação da poesia dos padrões descritivos. E assim, mais adiante junto aos românticos, abrem-se as portas para a poesia romântica universal progressiva, que "é capaz da formação mais alta e universal, não apenas de dentro para fora, mas também de fora para dentro" (Schlegel, 1997, p.64).

\section{Uma onda se forma no oceano: Herder}

Com Lessing e Winckelmann instaura-se um debate em torno do Laocoonte, traduzido na questão de saber se ele grita ou não, ou seja, coloca-se o problema da expressão ou da linguagem, enquanto passagem do fundo para a forma ou enquanto meio condutor e sustentáculo. E aqui talvez não deixe de ser interessante referir as investigações de Herder, quando ele nos diz que "a invenção da linguagem é para o homem tão natural como o fato de ser homem ... o homem evidencia reflexão quando a sua força espiritual se exerce tão livremente que, no oceano de impressões que a assalta por in-

5 O grupo de mármore do Laocoonte, formado por Laocoonte e seu dois filhos sendo atacados por duas serpentes, data provavelmente do I a. C. e foi esculpido em conjunto por Hagesandro, Atenodoros e Polidoros, tendo sido somente redescoberto na época moderna, em Roma, no dia 14 de janeiro de 1506, na presença de Michelângelo. Na época de Winckelmann, porém, ainda não se sabia a datação exata da obra e se a tomava como um exemplo da arte clássica grega. 
termédio de todos os sentidos, ela consegue, por assim dizer, isolar, suspender uma onda, dirigir para ela a sua atenção, e ter consciência do exercício dessa atenção" (Herder, 1987, p.55; 1975, p.24). Segundo Herder, o grande desafio para o homem, que faz dele um ser singular, reside em conseguir, por assim dizer, "pegar essa onda" (surfar!) em meio ao conjunto sensitivo que o define quando se depara com o mundo. "O homem chega ao mundo: imagine-se o oceano que duma só vez sobre ele se abate! A dificuldade com que aprende a distinguir, a conhecer seus sentidos, a usá-los isoladamente!" (idem, p.85; p.40).

Diante disso, o enfoque se desloca, pois o grito ou o gemido não surgem mais como possibilidade, mas como necessidade intrínseca do homem como homem. Com efeito, a alma humana, tomada em sua globalidade, torna-se "luminosa lei natural: eis um ser sensível, incapaz de encerrar dentro de si as vivas impressões que experimenta, um ser que no primeiro momento de espanto, ainda sem arbítrio e intenção, é obrigado a exprimir cada uma delas em voz alta" (idem, p.26; p.4). Trata-se agora de compreender o homem como se constituindo e se reconhecendo a si enquanto pura expressividade, de modo reflexivo num ato ou fluxo lingüístico, pois "a corda, uma vez posta em vibração, cumpre seu dever natural: ela soa!" (ibidem). A linguagem aparece então como a chave, não apenas como meio, e sim como concretização do traço distintivo [Merkmal] humano na constante passagem entre a sensibilidade e a reflexão, ${ }^{6}$ entre a sonoridade originária que nos liga aos animais e a consciência de si, que nos torna homens.

\section{E a onda se quebra na praia: Goethe}

Se Winckelmann e Lessing estavam atentos respectivamente ao princípio profundo e ao modo de como se tornam possíveis as características expressivas do Laocoonte, Goethe pergunta pelo ponto alto, culminante, da expressão, quando o meio alcança configuração ligando as profundezas com a superfície. Trata-se agora de perceber como e quando a linguagem é produtiva e artística, no instante mesmo em que se combinam a potência e o ato, isto é, indaga-se o processo criativo supremo. Em 1769, quando tinha 20 anos, Goethe visitou a sala de Antigüidades em Mannheim, onde se encontravam réplicas de gesso tanto do Laocoonte quanto do Apolo de Belve-

6 Herder emprega o termo alemão Besonnenheit, que poderia ser designado como uma reflexão prática e ativa, no sentido da prudência, ou seja, não possui um cunho meramente teórico. "O homem foi posto no estado de reflexão [Besonnenheit], que lhe é própria, e essa Besonnenheit (Reflexion), fazendo efeito pela primeira vez de modo livre, inventou a linguagem" (idem, p.55; p.23, tradução modificada). 
dere e do grupo de Castor e Polux, e estabeleceu uma perspectiva interpretativa para resolver a questão do grito de Laocoonte:

Minha atenção dirigia-se, sobretudo, para o Laocoonte, e resolvi de mim para mim a famosa questão de saber porque ele não grita, concluindo que não pode gritar. Essa primeira concepção explicou-me todos os atos e todos os movimentos do grupo. A atitude tão violenta como engenhosa da figura principal era composta de dois movimentos, a luta contra as serpentes, a fuga diante da mordida. A fim de mitigar essa dor, o baixo-ventre devia contrair-se, e isso tornava impossível o grito. Convenci-me igualmente de que o filho mais jovem não é mordido, e foi assim que procurei explicar ainda as belezas do grupo. (Goethe, 1986, v.2, p.38)

Anos mais tarde, no artigo Sobre o Laocoonte, de 1798, observando a obra de arte do ponto de vista da intersecção entre arte e natureza, Goethe considera que o instante de ação que nela é representado envolve três situações simultâneas: o pai, por ser ferido instantaneamente, suscita em nós um espanto ou um susto, ao passo que o filho mais novo, por ser fortemente sufocado e se encontrar apavorado implorando ajuda ao pai, nos leva a sentir opressão e temor e, por fim, a possibilidade que o filho mais velho ainda tem de se libertar do ataque das serpentes, nos fornece um consolo e gera uma esperança de que ainda possa salvar-se. Diante disso, Goethe aproxima a cena do grupo escultórico do Laocoonte ao movimento de uma onda no momento em que se quebra na praia. "Eu gostaria de dizer que, assim como o grupo se encontra agora, ele é um raio fixo, uma onda petrificada no instante em que atinge a praia" (idem, 2005, p.121).

Como compreender esse último ato ou desenlace, esse ponto culminante da configuração? Questão efetivamente "petrificadora", que talvez possamos iluminar pela entrada em cena do olhar produtivo, que se põe no interior do processo criativo e vislumbra de modo dramático o ápice. O bramido do mar, a onda que se forma desde o fundo rumo à superfície e a quebra na praia parecem indicar uma confluência suprema entre reflexão e criação, entre teoria e prática. Seria esse o alvo do saber sensível que se chama "estética", que estava então em vias de nascimento? Seja como for, Goethe tem uma resposta que é típica de seu gênio, ao dizer que "uma obra de arte autêntica, assim como uma obra da natureza, permanece sempre infinita para o nosso entendimento; ela é contemplada [angeschaut], sentida, faz efeito, mas não pode ser propriamente conhecida, muito menos sua essência, seu mérito podem ser expressos em palavras" (idem, p.115).

\section{Fim ou novo começo das aventuras mar adentro? Kant}

Mas, antes de terminar o passeio, façamos uma pequena parada ou um pequeno adendo ou excurso pelas metáforas marinhas da filosofia alemã, 
tendo em vista que nem todos as viram com bons olhos ou de maneira positiva. Há os que pretendem refrear os devaneios ou até mesmo acabar com as aventuras e ilusões, com os vôos e sobrevôos. Longe de compartilhar do otimismo leibniziano diante da idéia de abraçar o universo, Kant colocará um freio nesse delírio viajante e irá preferir, antes de tudo, perscrutar e delimitar cuidadosamente a terra firme, para dali aquilatar o oceano tenebroso (nórdico?), tal como ele nos diz no fim da analítica transcendental da Crítica da razão pura, trecho que ao mesmo tempo constitui uma entrada na dialética transcendental. O domínio do entendimento, essa terra, a saber,

\begin{abstract}
é uma ilha circunscrita pela natureza mesma por limites imutáveis. É a terra da verdade (um nome sedutor), envolta por um vasto e tempestuoso oceano, a verdadeira sede da ilusão, onde muito nevoeiro e muito gelo, em ponto de liquefazer-se, permitem imaginar falsamente novas terras e, enquanto iludem com vãs esperanças o navegador que vagueia sem rumo a procura de novas descobertas, enredam-no em aventuras, das quais não poderá jamais desistir e tampouco terminá-las. (Kant, 1983, p.267-8).
\end{abstract}

Diante dessas ameaças que surgem por todos os lados, Kant sugere uma atitude de resignação e de precaução.

Antes de arriscarmo-nos a esse mar para explorá-lo em toda a sua amplidão e alcançarmos a certeza de que é possível nele ter esperança de alguma coisa, será útil lançarmos antes um olhar sobre o mapa da terra que agora queremos abandonar e perguntar primeiramente se com o que ela contém em si não poderíamos ficar satisfeitos ou, no mínimo, termos necessariamente de ficar satisfeitos, caso não haja um chão em nenhum outro lugar, no qual possamos nos instalar [anbauen]; em segundo lugar, perguntar sob que título podemos nós mesmos possuir essa terra e nos manter seguros diante de todas as reivindicações mal intencionadas. (idem, p.268)

Embora prudente e cautelosa, como convém à tarefa crítica, não deixa de ser reveladora essa medida de segurança na associação do entendimento a uma ilha. Será, porém, esse chão tão seguro assim ou esse insulamento não provoca antes um desejo irreprimível e ainda mais forte para que nos lancemos de volta ao mar? Só que agora à toda carga, talvez embalados por ventos românticos e idealistas e quem sabe impulsionados por uma força mais elevada e grandiosa. Goethe percebeu essa tentação que o mestre de Könisberg lançou aos seus contemporâneos, ao dizer em uma máxima: "Kant deliberadamente se limita a um certo círculo e sempre aponta ironicamente para além dele". ${ }^{7}$ Logo no início do pós-kantismo, coube a Schiller

7 „Kant beschränkt sich mit Vorsatz in einen gewissen Kreis und deutet ironisch immer darüber hinaus" (Goethe, s.d., Maximen, p.258). 
seguir essa trilha. No breve ensaio "Sobre o sublime", Schiller pondera que é "o sublime que nos proporciona uma saída do mundo sensível, onde o belo gostaria de manter-nos confinados para sempre" (Schiller, 1955, p.99; 1991, p.58). E a imagem marinha que Schiller nos apresenta e com a qual eu gostaria de encerrar minha palestra refere-se a um episódio de "Les aventures de Telémaque, fils d'Ulysse" (1698), de Fénelon (1651-1715), resumido da seguinte maneira por Schiller:

A beleza, sob a figura de Calipso, enfeitiçou o valente filho de Ulisses, e graças ao poder de seus atrativos mantém-no longo tempo prisioneiro em sua ilha. Por muito tempo acredita ele estar prestando culto a uma imortal divindade, quando na verdade apenas repousa nos braços da volúpia; mas, sob a figura de Mentor, uma impressão sublime comove-o de repente; ele se lembra de sua destinação superior, lança-se às ondas e é livre. (idem, p.99-100; p.59)

WERLE, Marco Aurélio. The sea and the soul: marine metaphors in german land. Trans/Form/Ação, (São Paulo), v.30(1), 2007, p.225-234.

- ABSTRACT: The aim of this paper is to explore some marine metaphors in the german thought from Leibniz to Goethe, with the intention to indicate how certain aesthetic ideas (the conception of soul, language, artistic creation and the dialectic relation between form and content) acquire development and importance to a new enlarged vision of human being, not more determinated by the understanding, but by unconscious and affective elements. The investigation search ideas from Leibniz, Winckelmann, Herder, Goethe and Kant.

- KEYWORDS: aesthetics; german philosophy; Goethe's time; literature; art; philosophy.

\section{Referências bibliográficas}

BÄUMLER, Alfred. Das Irrationalitätsproblem in der Ästhetik und Logik des 18. Jahrhunderts. Darmstadt: WBG, 1967 (2. Ausgabe; 1. Ausgabe 1923).

GOETHE, J. W. "Sobre o Laocoonte", In: Escritos sobre arte. Introdução, tradução e notas de Marco Aurélio Werle. São Paulo: Humanitas/Imprensa oficial, 2005.

Die Leiden des jungen Werther. In: Digitale Bibliothek Band 1: Deutsche Literatur, S.50443-44 (vgl. Goethe-HA Bd. 6).

Memórias: poesia e verdade. Tradução de Leonel Vallandro. Brasília: Editora da UnB, 1986, v.2. 2ed.

Werke: Maximen und Reflexionen. In: Digitale Bibliothek Band 4: Goethe. S.8024 (vgl. Goethe-BA Bd. 18).

HERDER, J. G. Sprachphilosophie. Ausgewählte Schriften, Aus dem Gesamtwerk ausgewählt, mit einer Einleitung, Anmerkungen und Registern versehen von Erich Heintel. Hamburg: Meiner, 1975, 2. Auflage (1. Auflage, 1960). 
HERDER, J. G. Ensaio sobre a origem da linguagem. Tradução de José M. Justo. Lisboa: Antígona, 1987.

HÖLDERLIN, F. Reflexões. Tradução de Márcia de Sá Cavalcante e Antonio Abranches. Rio de Janeiro: Relume Dumará, 1994.

KANT, I. Kritik der reinen Vernunft. Werke. Org. por Wilhelm Weischedel. Darmstadt: WBG, v.3, 1983.

LEIBNIZ, Gottfried Wilhelm. Novos ensaios sobre o entendimento humano. Tradução de Luiz João Baraúna. Coleção Os pensadores. São Paulo: Abril Cultural, 1984.

SCHILLER. F. "Über das Erhabene". In: Schriften zum Theater, zur Philosophie der Ästhetik und der Geschichte. Stuttgarter Hausbücherei: Tübingen, 1955.

"Sobre o patético". In: Teoria da tragédia. Tradução de Flávio Meurer com introdução e notas de Anatol Rosenfeld. São Paulo: EPU, 1991.

SCHLEGEL, F. O dialeto dos fragmentos. Tradução, apresentação e notas de Márcio Suzuki. São Paulo: Iluminuras, 1997.

WAGNER. Guia do Ouvinte. Coleção Clássica A história dos gênios da música. São Paulo: Círculo do Livro, 1989.

WINCKELMANN, J. J. Gedanken über die Nachahmung der griechischen Werke in der Malerei und Bildhauerkunst. Reclam: Stuttgart, 1995.

Reflexões sobre a arte antiga. Estudo introdutório de Gerd A. Bornheim, tradução de Herbert Caro e Leonardo Tochtrop, Porto Alegre: Movimento, 1975.

Geschichte der Kunst des Altertums. Darmstadt: WBG, 1993.

Beschreibung des Torso im Belvedere zu Rom. Digitale Bibliothek Band

1: Deutsche Literatur (vgl. Winckelmann-BDK). 